\title{
Control of allergic rhinitis and asthma test - a formal approach to the development of a measuring tool
} Luis Nogueira-Silva1', Sonia V Martins'1, Ricardo Cruz-Correia ${ }^{2}$, Luis F Azevedo², Mario Morais-Almeida33, António Bugalho-Almeida4, Marianela $\mathrm{Vaz}^{5}$, Altamiro Costa-Pereira ${ }^{2}$ and Joao A Fonseca*6

\begin{abstract}
Address: ${ }^{1}$ Serviço de Biostatística e Informática Médica, Faculdade de Medicina da Universidade do Porto, Porto, Portugal, ${ }^{2}$ Serviço de Biostatística e Informática Médica and CINTESIS - Centro de Investigação em Tecnologias e Sistemas de Informação em Saúde, Faculdade de Medicina da Universidade do Porto, Porto, Portugal, ${ }^{3}$ Clínica Universitária de Pneumologia, Faculdade de Medicina da Universidade de Lisboa and Unidade de Imunoalergologia, Hospital CUF-Descobertas, Lisboa, Portugal, ${ }^{4}$ Clínica Universitária de Pneumologia, Faculdade de Medicina da Universidade de Lisboa and Centro Hospitalar Lisboa Norte, Lisboa, Portugal, ${ }^{5}$ Associação Portuguesa de Asmáticos, Porto, Portugal and ${ }^{6}$ Serviço de Biostatística e Informática Médica, CINTESIS - Centro de Investigação em Tecnologias e Sistemas de Informação em Saúde and Faculdade de Medicina da Universidade do Porto and Serviço de Imunoalergologia, Hospital de S. João, EPE, Porto, Portugal
\end{abstract}

Email: Luis Nogueira-Silva - luis.nsilva@netcabo.pt; Sonia V Martins - soniavilarmartins@portugalmail.pt; Ricardo Cruz-

Correia - rcorreia@med.up.pt; Luis F Azevedo - lazevedo@med.up.pt; Mario Morais-Almeida - mmoraisalmeida@netcabo.pt; António BugalhoAlmeida - bugalho.almeida@hsm.min-saude.pt; Marianela Vaz - marianelavaz@sapo.pt; Altamiro Costa-Pereira - altamiro@med.up.pt; Joao A Fonseca* - jfonseca@med.up.pt

* Corresponding author

Published: 17 June 2009

Respiratory Research 2009, 10:52 doi:10.1 186/1465-9921-10-52
Received: 6 March 2009

Accepted: 17 June 2009

This article is available from: http://respiratory-research.com/content/10/1/52

(c) 2009 Nogueira-Silva et al; licensee BioMed Central Ltd.

This is an Open Access article distributed under the terms of the Creative Commons Attribution License (http://creativecommons.org/licenses/by/2.0), which permits unrestricted use, distribution, and reproduction in any medium, provided the original work is properly cited.

\begin{abstract}
Background: The concurrent management of allergic rhinitis and asthma (ARA) has been recommended by Allergic Rhinitis and its Impact on Asthma (ARIA) guidelines. However, a tool capable of assessing simultaneously the control of upper and lower airways diseases is lacking.
\end{abstract}

Aim: To describe the studies conducted to design the control of ARA test (CARAT) questionnaire.

Methods: We performed a literature review to generate a list of potentially important items for the assessment of control of ARA. A formal consensus development process, that used an innovative web-based application, was designed - III experts in ARA and 60 patients participated. At the final consensus meeting, 25 primary and secondary care physicians formulated the questions and response options. A qualitative feasibility study $(n=3$ I patients) was conducted to evaluate the comprehensibility of the questionnaire while testing two different designs.

Results: Thirty-four potentially important items were identified. All the steps of the consensus process were completed in 2.5 months. The opinions of experts and patients lead to the formulation of 17 questions. At the feasibility study the instructions and wording problems were corrected and a semi-tabular format was chosen.

Conclusion: A tool to measure the control of allergic rhinitis and asthma was developed using a comprehensive set of methodological steps ensuring the design quality and the face and content validity. Additional validation studies to assess the psychometric properties of the questionnaire have started. 


\section{Introduction}

Allergic rhinitis and asthma (ARA) are inflammatory diseases and are often associated. The lack of control of these diseases is responsible for a significant loss in patient's quality of life and an important socioeconomic burden $[1,2]$. According to international guidelines, achievement of disease control is the primary goal for the treatment of allergic respiratory diseases $[1,3]$. Allergic Rhinitis and its Impact on Asthma (ARIA) [1] guidelines have recently emphasized in the importance of a combined approach for both evaluation and management of ARA. Thus, measurement of disease control should consider, concurrently, the pathologies of upper and lower airways [4].

Based on the definition of asthma control of the Global Initiative for Asthma [3], chronic disease control can be characterized as patients experiencing minimal symptoms, having no limitations in their activities, having minimal requirement for rescue medications, having near normal physiological function, and experiencing infrequent exacerbations.

In addition to quality of life questionnaires, symptoms and severity scores [5-9], several questionnaires for assessing control have been developed for asthma in the last 10 years [10-13]. To a lesser extent the same has happened for allergic rhinitis [14-16] and control questionnaires are being validated [1]. However, no questionnaire for measuring the control of ARA concurrently has been developed. In fact, only Rhinasthma [15] assesses ARA concurrently, but it is designed for evaluation of healthrelated quality of life impairment.

The "Control of Allergic Rhinitis and Asthma Test" (CARAT) project [17] aims to develop a brief self-administered tool to quantify the degree of control of ARA in adult patients with a previous medical diagnosis of ARA.

A fundamental phase for the accuracy and usefulness of such a tool is its early development. A recent systematic review recommended that these early steps should include different methods to ensure the quality of the questionnaire's design [18].

In this article, we aimed to describe the studies conducted to design the Control of Allergic Rhinitis and Asthma Test questionnaire, namely an item generation process, a formal web-supported consensus process and a qualitative feasibility study.

\section{Questionnaire development}

Conceptually, this tool was developed as a self-administered questionnaire to quantify the degree of control in adult patients with a previous diagnosis of ARA, to be applicable both in clinical practice and research settings. Therefore, it should be short and easy to complete [19], while being suitable to assess both individual variations and discriminate between groups of patients with different levels of control.

The questionnaire development comprised 3 fundamental steps: I) an item generation process, II) a formal consensus process and III) a feasibility study. These steps are described and discussed independently below.

\section{Item generation process \\ Methods}

We performed a literature search in the Scopus database (which includes Medline and EMBASE) [20] with the following keywords: 'asthma', 'rhinitis', 'conjunctivitis', 'questionnaire', 'symptom score', 'control' and 'quality of life' which retrieved a total of 2693 articles. Additional questionnaires were retrieved from papers' references and from studies known to the authors. All the questionnaires were classified according to their purposes and diseases assessed. All their questions were tabulated. The list with all the questions was progressively reduced by first eliminating the questions not related to ARA, then the questions which were repeated or had similar meaning and finally those not related to control. The remaining questions were sorted into 10 classes (Lower airways symptoms, Nasal symptoms, Ocular symptoms, Oropharyngeal symptoms, Other symptoms, Activities, Sleep impairment, Psychosocial impact, Treatment and Exacerbation). This process allowed us to generate a list of potentially important items for the assessment of control of ARA (figure 1).

\section{Results}

A total of 29 different questionnaires were identified. Only 4 questionnaires assessed disease control and were related to asthma control. The 29 questionnaires comprised 425 questions from which 116 were selected (figure 1). Thirty-four individual potentially important items were identified from the questions (figure 2) and were used in the consensus process.

\section{Discussion}

The item generation derived from the comprehensive review of the existing literature, unlike the development of asthma control questionnaires [11-13].

It led to the creation of a list with all aspects related to the control of ARA. Moreover, both experts and patients were asked to suggest additional items in the following rounds.

\section{Formal consensus process Methods}

A formal consensus development process was designed, informed by the Nominal Group Technique model modified by the RAND Corporation [21]. It comprised 1) a public presentation of the project at a national confer- 


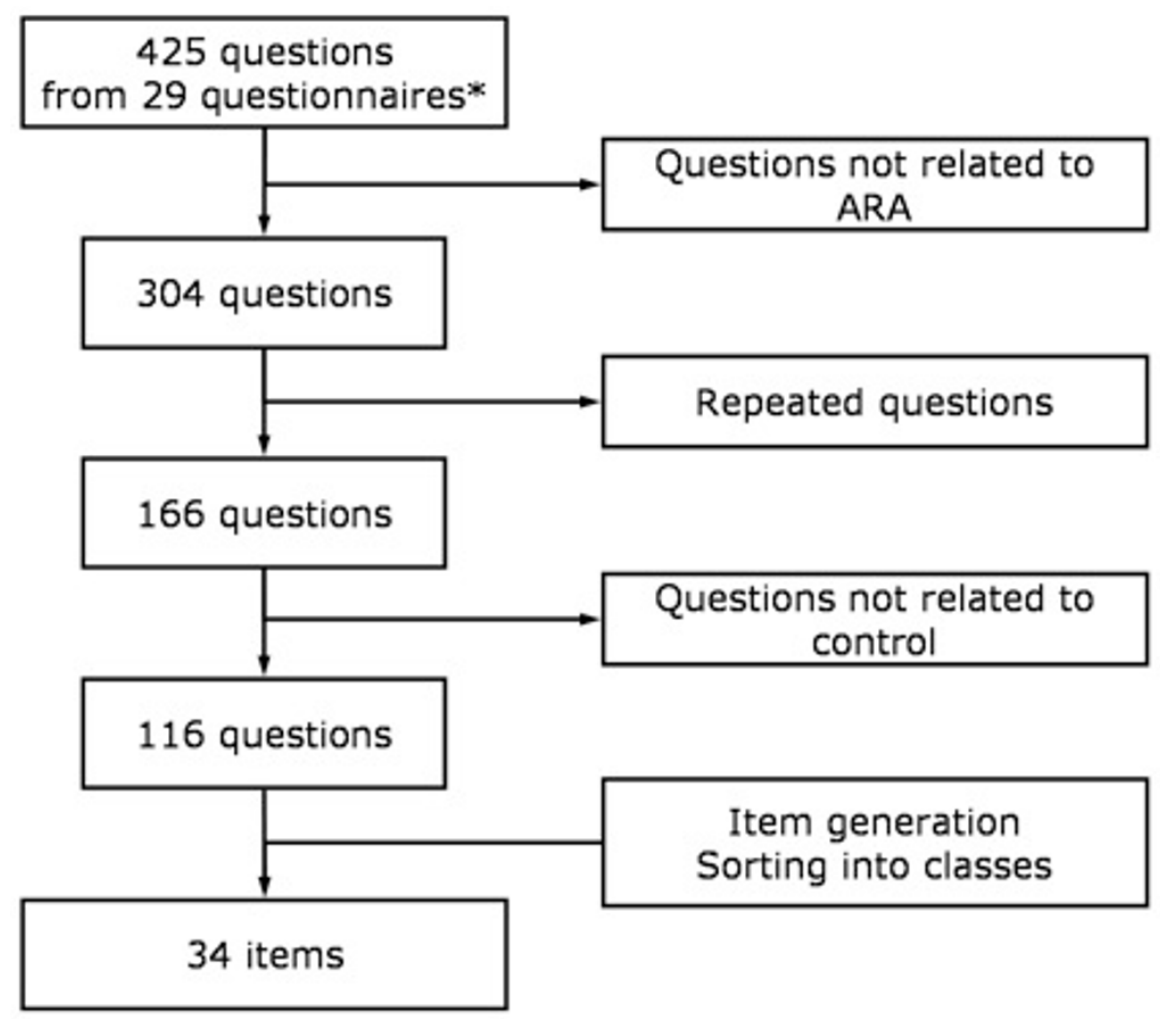

Figure I

Item generation flowchart. From the questions retrieved from published questionnaires, the potentially important items were identified. *four were asthma control questionnaires; none were allergic rhinitis control questionnaires; 6 assessed ARA concurrently but none its control.

ence, 2) two rounds of experts' contribution via a web application with feedback after each round, 3 ) a round of patients' contribution and 4) a final consensus conference.

\section{Initial meeting}

The project's objectives and outline were presented at the 2007 national annual meeting of the Portuguese Allergology and Clinical Immunology Society within a session that discussed the control of ARA. The audience was invited to answer questions related to the importance of a single questionnaire assessing simultaneously the control of allergic rhinitis and asthma, its appropriateness, usefulness and possible designs, using an on-site televoting system with immediate feedback. The audience responses are presented as proportions of the respondents for each question; between 28 and 55 delegates answered the different questions.

\section{Experts' contributions}

Portuguese experts in ARA were invited to participate in the consensus process by email. The email addresses $(\mathrm{n}=$ 276) were provided by national scientific societies (Portuguese Allergology and Clinical Immunology Society and the Portuguese Pneumology Society) and other organized groups with interest in ARA.
A total of 111 (40\%) experts participated: 81 participated in the first round and 82 in the second. Fifty-two experts participated in both rounds.

A web-based application was developed to allow online interaction with the experts. It gathered theirs input, provided them feedback at the end of each round, facilitated the data gathering and analysis, while maintaining anonymity of the answers (for further details see Additional file 1).

In the first round, each participant was asked to choose 15 items, either from the list of items generated previously or by suggesting new ones. Then, he/she was asked to rank those items by importance. Finally, for each of the chosen items, the participant had to choose between different characteristics of the items such as intensity or frequency.

For each item, a weighted score was calculated as the inverse of the proportion of participants who had chosen it, multiplied by the sum of its rankings. The items were ranked by this score and plotted in a bar graph.

A shortlist was elaborated with the items with the highest scores. This shortlist had to include at least two specific 


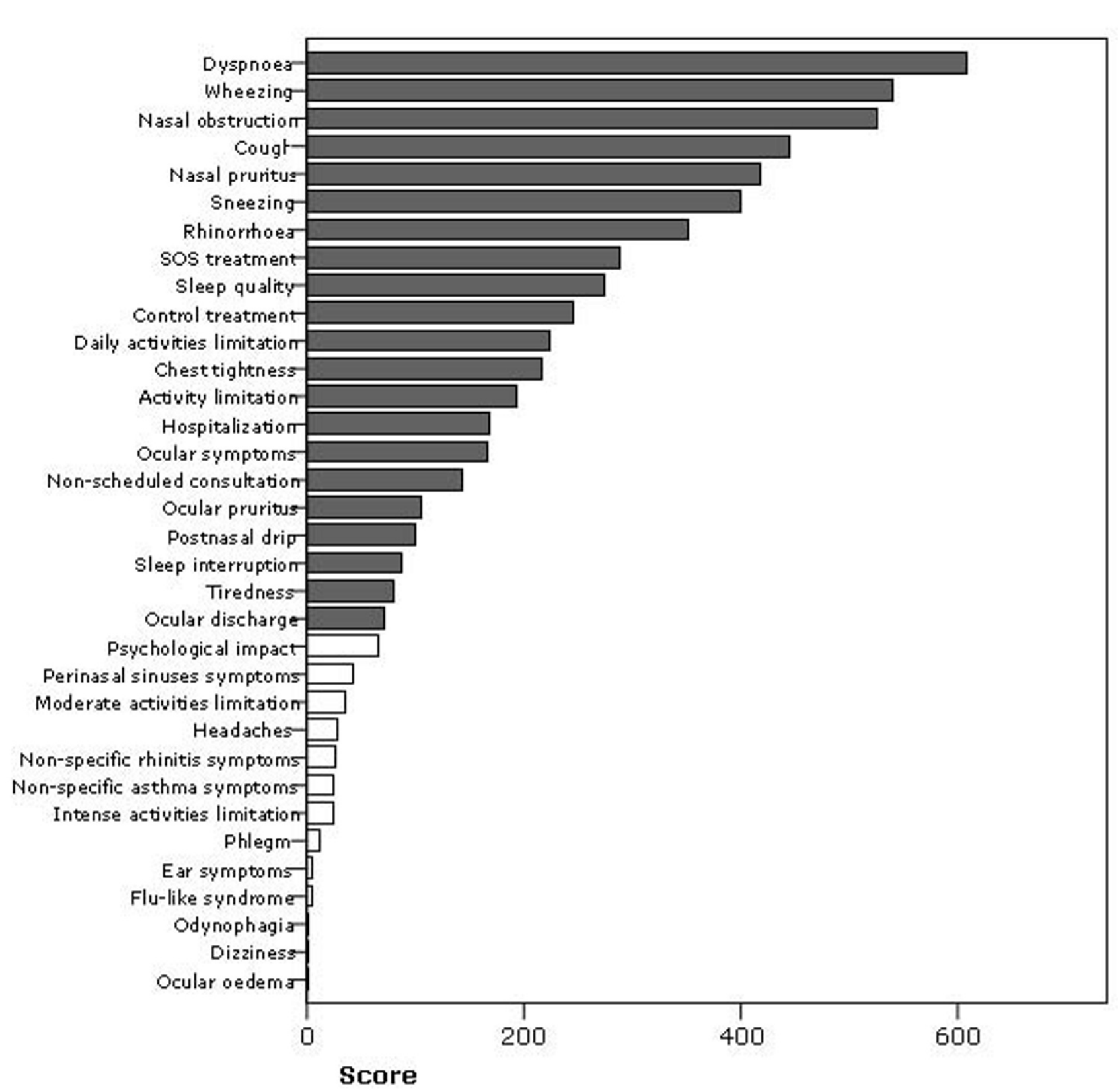

Figure 2

Sorted items. The 34 items from the item generation phase are presented, ranked by their score (inverse of the proportion of participants who chose the item, multiplied by the sum of its rankings). The shortlist (filled bars) included the highest scored items and the only item suggested by the participants ("Work/school absenteeism").

items from each class. In addition, the new items suggested by the participants were added to the shortlist.

In the second round, the participants were presented the shortlist of items generated at the end of the first round, grouped by classes, and were asked to rank the items within their classes. For each item we calculated the inverse of its average ranking, and multiplied it by the number of items in its class.

In addition, the participants were asked to choose the type of response options for each item between Visual Analogue Scales (VAS), different Likert scales or dichotomic scale. Standard descriptive statistical techniques were used. 


\section{Patients' contribution}

Sixty patients with ARA were enrolled at a hospital-based allergy outpatient clinic. Patients older than 18 years of age, with a medical diagnosis of ARA, able to read and fill the questionnaire and without other respiratory conditions were eligible for participation. Fifty-four were women, the average (standard deviation) age was 35 (14.4) years. Seventeen (29\%) patients had four years of school education, 20 (35\%) had less than twelve and 21 (36\%) had twelve or more years of school education; 2 patients didn't provide this information.

The data was collected by a psychologist trained in questionnaire development. The patients were presented a paper form with the shortlist of items generated at the end of the experts' first round, grouped by classes. They were invited to suggest new items. Then, as in the experts' second round, the patients were asked to rank the items within their classes. For each item we calculated the inverse of its average ranking, multiplied it by the number of items in its class and summarized it in a table.

\section{Final meeting}

Twenty-five Allergologists, Pneumologists and General Practitioners, with a special interest in ARA, from different regions of Portugal, were invited to participate in the final consensus meeting, independently of having or not participated previously in the project.

The session started with an oral presentation of the results of the previous rounds.

Subsequently, the participants were divided in 3 groups. Each group was attributed around 12 items belonging to 2 or 3 classes. The group was asked to discuss the results from the previous rounds and formulate a question and the response options for each item attributed to them. The authors provided the participants with examples of questions from existing questionnaires.

All participants were individually asked to score each item from 1 to 9 according to its importance ( 1 being the lowest). This data was processed on-site, presented to the panel and used to stimulate the discussion.

Finally, the panel was reassembled and discussed all the questions, focusing on different aspects related to the items and their importance, the wording of the questions, the response options and the timeframe to be assessed. At the end of the discussion, consensus was reached for all questions.

The meeting lasted approximately 7 hours.

\section{Results \\ Initial meeting}

At the initial public presentation, four fifths of the audience $(81 \%)$ considered that questionnaires assessing the control of ARA would be useful for the clinical practice. Moreover, four fifths (81\%) preferred a single questionnaire assessing ARA concurrently rather than 2 separate questionnaires. Nearly half (48\%) considered 4 weeks to be the best time-period to be assessed in the questions. Nearly half (47\%) considered that the questions should assess the frequency rather than the intensity of the symptoms while around one third (38\%) considered that the option between frequency and intensity should be made for each individual question. More than half (59\%) considered the best scale for the response options to be a Likert scale (with 4 points $(26 \%), 5$ points $(20 \%)$ or 3 points $(13 \%))$, nearly one third (32\%) preferred a VAS, while $9 \%$ preferred a dichotomic (Yes/No) scale.

\section{Experts' and patients' contribution}

In the first round each expert chose 15 items and sorted them by order of importance. Nine out of the 81 participants $(11 \%)$ only chose 15 items and didn't sort them by importance. The score calculated for each item is presented in figure 2 .

After the first round, the shortlist had 22 items, including the only item suggested by the participants - "Work/ school absenteeism".

Globally, for the 22 items, the participants preferred frequency rather than intensity.

The experts, in their second round, and the patients were asked to rank the 22 items within their classes. The comparison of the ranking by the 2 groups can be seen in table 1. Some differences occurred, mainly in the Nasal symptoms class and the Activities class. The greatest difference occurred with the item "Tiredness".

As for the type of response options, the experts preferred a Likert scale for 16 items while a dichotomic (Yes/No) scale was preferred for the remaining 6 items ("Work/ school absenteeism", "Postnasal drip", "Ocular symptoms", "Control treatment", "Non-scheduled consultation" and "Hospitalization"). The VAS wasn't preferred for any of the items; in fact it was the least chosen option and its highest proportion of choice was 37\%, for the item "Nasal obstruction".

\section{Final meeting}

Within three groups, the physicians discussed and formulated the questions and response options for the items distributed to each group. 
Table I: Items ranked within classes by the experts $(n=82)$ at the second round and by patients $(n=60)$.

\begin{tabular}{|c|c|c|}
\hline & Experts & Patients \\
\hline \multicolumn{3}{|l|}{ Lower airways symptoms } \\
\hline Dyspnoea & 2,62 & 2,22 (I st) \\
\hline Wheezing & 1,80 & $1,95\left(2^{\text {nd }}\right)$ \\
\hline Cough & 1,35 & $I, 4^{\prime}\left(4^{\text {th }}\right)$ \\
\hline Chest tightness & 1,21 & $1,46\left(3^{r d}\right)$ \\
\hline \multicolumn{3}{|l|}{ Nasal symptoms } \\
\hline Nasal obstruction & 2,81 & I,84 (2nd $)$ \\
\hline Sneezing & 1,80 & 1,95 (1 st) \\
\hline Rhinorrhoea & 1,67 & $\mathrm{I}, 55\left(4^{\text {th }}\right)$ \\
\hline Nasal pruritus & 1,58 & $\mathrm{I}, 84\left(2^{\mathrm{nd}}\right)$ \\
\hline Postnasal drip & 1,17 & $1,32\left(5^{>\text {th }}\right)$ \\
\hline \multicolumn{3}{|l|}{ Ocular symptoms } \\
\hline Ocular pruritus & 2,02 & 2,17 ( $\left.\left.\right|^{\text {st }}\right)$ \\
\hline Ocular symptoms & 1,40 & $\mathrm{I}, 2\left(3^{\mathrm{rd}}\right)$ \\
\hline Ocular discharge & 1,27 & $1,42\left(2^{\text {nd }}\right)$ \\
\hline \multicolumn{3}{|l|}{ Activities } \\
\hline Daily activities limitation & 2,45 & $\mathrm{I}, 80\left(2^{\text {nd }}\right)$ \\
\hline Activity limitation & 1,80 & $1,47\left(3^{r d}\right)$ \\
\hline Work/school absenteeism & 1,31 & $1,13^{\left(4^{\text {th }}\right)}$ \\
\hline Tiredness & 1,30 & 2,64 (1 st) \\
\hline \multicolumn{3}{|l|}{ Sleep impairment } \\
\hline Sleep interruption & 1,37 & $|, 4|(\mid$ st $)$ \\
\hline Sleep quality & 1,30 & $1,26\left(2^{\text {nd }}\right)$ \\
\hline \multicolumn{3}{|l|}{ Treatment } \\
\hline Control treatment & 1,59 & I,67 ( Ist $^{\text {st }}$ \\
\hline SOS treatment & 1,15 & $I, I I\left(2^{\text {nd }}\right)$ \\
\hline \multicolumn{3}{|l|}{ Exacerbation } \\
\hline Non-scheduled consultation & $\mathbf{I , 4 I}$ & I,36 ( Ist $^{\text {st }}$ \\
\hline Hospitalization & 1,26 & $1,30\left(2^{\text {nd }}\right)$ \\
\hline
\end{tabular}

The items are shown ranked according to the inverse of their average ranking by the participants, multiplied by the number of items in the class. In bold are the items with highest score and in brackets are indicated the order of the ranking by patients. Differences between experts and patients are seen in the Nasal symptoms class ("Sneezing" and "Nasal obstruction") and the Activities class ("Tiredness").

The discussion led to the formulation of 17 questions. The item "Postnasal drip", which had a low ranking, was substituted by a more general item "Throat complaints, like pruritus or postnasal drip". The 3 items regarding Ocular symptoms, generally low ranked, were aggregated in a single question. The panel considered the items "Activity limitation", "Daily activities limitation" and "Tiredness" redundant and rephrased these items. The possibility of including "Sports activities absenteeism" in the question referring to the item "Work/school absenteeism" was discussed. The item "Sleep quality" was considered to have different interpretations and was replaced by "Symptoms/ complaints after awaking". The items "Control treatment" and "SOS treatment" were aggregated in one single question as "Increase in the use of medication".

The panel decided that 4 weeks should be the timeframe used for every question. It was considered a period long enough to have a perspective on control without great distortion of the patients recollection of events.
When applicable, all the questions referred to frequency of occurrence, rather than intensity. The response options for the questions related to Lower airways symptoms, Nasal symptoms, Ocular symptoms, Sleep impairment and Activities (apart from "Work/school/sports activities absenteeism") should be 4-points Likert scales. For each class the response options were formulated according to the existing guidelines. For the remaining questions, a dichotomic (Yes/No) scale was used.

The participants agreed to test, in the following feasibility study, two versions of the questionnaire, one with a question-answer format and another with a tabular format.

The whole formal consensus process was completed in 2.5 months.

\section{Discussion}

A formal consensus process was designed to reduce the number of items, determining which should be included in the questionnaire. To do so, it was considered necessary to obtain the opinions of experts in ARA but also to have a contribution from patients with ARA, unlike other studies which only include patients in the feasibility or validation studies [11-13].

The communication with the experts was considerably simplified by the use of an innovative web-based platform. This platform allowed to contact a large number of experts in ARA, made the data collection and processing more efficient while maintaining the safety and anonymity of the information and allowed to provide the participants with feedback on the rounds' results.

In this way, the contribution of ARA experts and patients through several steps with different methodological approaches, allowed the identification of 22 important items to assess the control of these diseases. The importance given to the items progressively converged. Discrepancies occurred in a few items, particularly in the "Activities" and "Nasal symptoms" classes. These discrepancies may result from different interpretations of the concepts to which the items refer to. For instance, during the consensus meeting, experts considered "Activities limitation" to be equivalent to what patients considered "Tiredness". Moreover, the gender imbalance in the patients sample may have contributed for these differences.

The final meeting allowed for a thorough discussion of the items and formulation of the questions and the response options for the questionnaire by primary and secondary care physicians.

ARIA proposes VAS to be used in the evaluation of rhinitis severity [1]. This approach has been successfully tested in 
recent studies. However, both at the initial meeting and at the consensus rounds, the experts preferred either Likert scales or dichotomic (Yes/No) scales as the response options for all the items.

\section{Feasibility study \\ Methods}

Thirty-one patients with ARA were enrolled at a hospitalbased allergy outpatient clinic. Patients older than 18 years of age, with a medical diagnosis of ARA, able to read and fill the questionnaire and without other respiratory conditions were eligible for participation. Twenty-eight were women, the average (standard deviation) age was 32 (14.6) years. Six (19\%) patients had four years of school education, 12 (39\%) had less than twelve and 13 (42\%) had twelve or more years of school education.

The data was collected by a psychologist trained in questionnaire development.

The patients were presented two versions of the questionnaire, different in their format. In the first version each question was followed by its response options (questionanswer format). In the second version, the questions and response options were presented as tables (tabular format). Both versions started with a short sentence with the filling instructions.

All patients completed both versions of the questionnaire, alternately starting with either the tabular format version or the question-answer format version. Sixteen patients completed the tabular format questionnaire first. The time they took to complete each version was measured. The difficulties each patient had while completing each version were registered, as well as their opinions regarding the wording and comprehensibility of the questions. The preferred version and the reasons for the choice were also enquired. The data was processed with standard descriptive statistic techniques.

\section{Results}

Overall the patients presented few difficulties completing either version. Two patients needed assistance to fill the questionnaire.

Regarding the tabular format, 19 patients didn't report any difficulties. Seventeen comments were registered, 9 of them regarding the instructions of the questionnaire and 6 related to the wording of the questions.

As for the question-answer format, 21 patients didn't report any difficulties filling the questionnaire. Thirteen comments were registered, 5 of them concerning the wording of the questions and 5 related to the response options.
Twenty-three patients (74\%) preferred the tabular format and all stated this version was easier and quicker to fill. All those who preferred the question-answer format considered it to be easier to understand, with more detailed information.

The patients took on average (standard deviation) 3' (3.1) to fill the tabular format version (minimum 1', maximum $\left.12^{\prime}\right)$ and $5 '$ (4.9) to fill the question-answer format version (minimum 2', maximum 20'). The patients took on average (standard deviation) 1.9' (2.29) less to fill the tabular version of the questionnaire.

\section{Discussion}

The comments of the patients were used to construct a final version of the questionnaire, correcting important issues. In the final version, greater emphasis was given to the instructions of the questionnaire, since the disregard of these directives was one of the biggest problems found. The wording of some questions was altered to increase comprehensibility. The wording of the response options was changed as it was judged preferable to maintain the same options throughout the questionnaire.

The test of two different formats of the questionnaire showed that the tabular format was preferred by most patients and was quicker to complete. These results weren't influenced by the order of administration of the 2 versions of the questionnaire (data not shown). However, $26 \%$ of the patients considered the question-answer format to be easier to understand. The chosen layout for the questionnaire was a semi-tabular format, in order to make it as clear as possible to the patients.

\section{Conclusion}

We describe a formal methodological approach for the development of a tool to concurrently measure the control of allergic rhinitis and asthma, in previously diagnosed adult patients.

Questionnaires for the assessment of control of either asthma or rhinitis are in use or under development. However, a tool capable of assessing simultaneously the control of upper and lower airways diseases was lacking.

The questionnaire now developed achieves this purpose (the direct English translation from Portuguese version is available in submitted Additional file 2). However, it has 17 questions, a considerable number that may hinder its use in some settings. Additional studies to evaluate the questionnaire's psychometric properties, reduce the number of items through analytical processes, establish the scoring system and assess its usefulness in clinical practice are being carried out. 
Moreover, we propose a questionnaire development approach with a sequence of qualitative methods, including an innovative consensus process, supported by web technologies. It was designed to allow for a large participation of stakeholders, drawing together the opinions of experts and patients.

This proposal is in agreement with recently published quality criteria for questionnaire development [18] and its different procedures were carried out in order to ensure the face and content validity and the overall quality of the instrument's design.

\section{Abbreviations}

ARA: allergic rhinitis and asthma; ARIA: Allergic Rhinitis and its Impact on Asthma; CARAT: Control of Allergic Rhinitis and Asthma Test; PHP: Hypertext Preprocessor; VAS: visual analogue scale.

\section{Competing interests}

The authors declare that they have no competing interests.

\section{Authors' contributions}

LNS participated in data collection, analysis and wrote the manuscript draft, SVM participated in data collection and analysis and reviewed the manuscript, RCC participated in study design, web application design, data analysis and reviewed the manuscript; LFA participated in study design, data analysis and reviewed the manuscript, MMA, $\mathrm{ABM}$ and $\mathrm{MV}$ participated in the study conception, led the consensus meeting and reviewed the manuscript, ACP participated in the study design and manuscript writing, JAF is responsible for the CARAT project and participated in all stages and tasks. All authors have read and approved the final manuscript.

\section{Additional material}

\section{Additional file 1}

Description of the use of a web application in the consensus process for the development of the Control of Allergic Rhinitis and Asthma Test (CARAT). The data provide more details on the development and use of the web-based consensus application.

Click here for file

[http://www.biomedcentral.com/content/supplementary/14659921-10-52-S1.doc]

\section{Additional file 2}

CARAT - Control of Allergic Rhinitis and Asthma Test. This is a translation to English of the of the preliminary version of Control of Allergic Rhinitis and Asthma Test, the development of which is described in this paper.

Click here for file

[http://www.biomedcentral.com/content/supplementary/14659921-10-52-S2.doc]

\section{Acknowledgements}

We thank the Portuguese Allergology and Clinical Immunology Society, the Portuguese Pneumology Society and the Portuguese Asthma Patients Association for their collaboration in the project, Luís Delgado, MD, PhD for his thoughtful comments on the manuscript, Ma Graça Castelo-Branco, MD for providing the conditions for data collection. We thank all participants of the consensus process and the patients for their time and help. Supported by an unrestricted grant from Merck Sharp \& Dohme Portugal.

\section{List of participants in the Final meeting of the Formal Consensus} Process

Ana Arrobas

Ana Todo-Bom

Ângela Gaspar

Aurora Carvalho

Carlos Alves

Carlos Lopes

Fernando Calvário

Filipe Inácio

Filomena Falcão

Graça Castelo-Branco

Jaime Correia-Sousa

João Almeida Fonseca

José Costa Trindade

José Dias-Pereira

José Moreira-Silva

Josefina Rodrigues

Manuel Branco

Manuel Luciano

Margarida Trindade

Rita Câmara

Rodrigo Alves

Rui Costa

\section{References}

I. Bousquet J, Khaltaev N, Cruz AA, Denburg J, Fokkens WJ, Togias A, Zuberbier T, Baena-Cagnani CE, Canonica GW, Van Weel C, Agache , Ait-Khaled N, Bachert C, Blaiss MS, Bonini S, Boulet L-P, Bousquet P-J, Camargos P, Carlsen K-H, Chen Y, Custovic A, Dahl R, Demoly $P$, Douagui H, Durham SR, Van Wijk RG, Kalayci O, Kaliner MA, Kim Y-Y, Kowalski ML, Kuna P, Le LTT, Lemiere C, Li J, Lockey RF, Mavale-Manuel S, Meltzer EO, Mohammad Y, Mullol J, Naclerio R, 
O'Hehir RE, Ohta K, Ouedraogo S, Palkonen S, Papadopoulos N, Passalacqua G, Pawankar R, Popov TA, Rabe KF, Rosado-Pinto J, Scadding GK, Simons FER, Toskala E, Valovirta E, Van Cauwenberge P, Wang D-Y, Wickman M, Yawn BP, Yorgancioglu A, Yusuf OM, Zar H, Annesi-Maesano I, Bateman ED, Kheder AB, Boakye DA, Bouchard J, Burney P, Busse WW, Chan-Yeung M, Chavannes NH, Chuchalin A, Dolen WK, Emuzyte R, Grouse L, Humbert M, Jackson C, Johnston SL, Keith PK, Kemp JP, Klossek J-M, Larenas-Linnemann D, Lipworth B, Malo J-L, Marshall GD, Naspitz C, Nekam K, Niggemann B, Nizankowska-Mogilnicka E, Okamoto Y, Orru MP, Potter P, Price D, Stoloff SW, Vandenplas O, Viegi G, Williams D: Allergic Rhinitis and its Impact on Asthma (ARIA) 2008 update (in collaboration with the World Health Organization, GA2LEN and AllerGen). Allergy: European Journal of Allergy and Clinical Immunology 2008, 63(SUPPL 86):8-160.

2. Bousquet J, Bousquet PJ, Godard P, Daures JP: The public health implications of asthma. Bulletin of the World Health Organization 2005, 83(7):548-554.

3. Global Strategy for Asthma Management and Prevention, Global Initiative for Asthma (GINA) 20072007 [http:// www.ginasthma.org].

4. Braunstahl G], Fokkens $W$ : Nasal involvement in allergic asthma. Allergy: European Journal of Allergy and Clinical Immunology 2003, 58(I 2): I 235- 1243.

5. Juniper EF, Guyatt GH, Epstein RS, Ferrie PJ, Jaeschke R, Hiller TK: Evaluation of impairment of health related quality of life in asthma: Development of a questionnaire for use in clinical trials. Thorax 1992, 47(2):76-83.

6. Marks GB, Dunn SM, Woolcock AJ: An evaluation of an asthma quality of life questionnaire as a measure of change in adults with asthma. Journal of Clinical Epidemiology 1993, 46(10): II03-IIII.

7. Kilpelaïnen M, Terho EO, Helenius $\mathrm{H}$, Koskenvuo M: Validation of a new questionnaire on asthma, allergic rhinitis, and conjunctivitis in young adults. Allergy: European Journal of Allergy and Clinical Immunology 200I, 56(5):377-384.

8. Revicki DA, Leidy NK, Brennan-Diemer F, Sorensen S, Togias A: Integrating patient preferences into health outcomes assessment: The multiattribute asthma symptom utility index. Chest 1998, I I4(4):998-1007.

9. Fonseca JA, Delgado L, Costa-Pereira A, Tavares C, Moreira A, Morete A, de Oliveira F, Rodrigues J, Vaz M: Evaluation of the Asthma Life Quality test for the screening and severity assessment of asthma. Allergy: European Journal of Allergy and Clinical Immunology 2004, 59( I I): I I 98-I 204.

10. Boulet LP, Boulet V, Milot J: How should we quantify asthma control? A proposal. Chest 2002, I 22(6):2217-2223.

II. Juniper EF, O'Byrne PM, Guyatt GH, Ferrie PJ, King DR: Development and validation of a questionnaire to measure asthma control. European Respiratory Journal 1999, 14(4):902-907.

12. Nathan RA, Sorkness CA, Kosinski M, Schatz M, Li JT, Marcus P, Murray JJ, Pendergraft TB: Development of the Asthma Control Test: A survey for assessing asthma control. Journal of Allergy and Clinical Immunology 2004, I I3(I):59-65.

13. Vollmer WM, Markson LE, O'Connor E, Sanocki LL, Fitterman L, Berger M, Buist AS: Association of asthma control with health care utilization and quality of life. Am J Respir Crit Care Med. 1999, I60(5 Pt I): 1647-1652.

14. Juniper EF, Guyatt GH: Development and testing of a new measure of health status for clinical trials in rhinoconjunctivitis. Clinical and Experimental Allergy |99|, 2I(I):77-83.

15. Baiardini I, Pasquali M, Giardini A, Specchia C, Passalacqua G, Venturi S, Braido F, Bonini S, Majani G, Canonica GW: Rhinasthma: A new specific QoL questionnaire for patients with rhinitis and asthma. Allergy: European Journal of Allergy and Clinical Immunology 2003, 58(4):289-294.

16. Bousquet PJ, Combescure C, Neukirch F, Klossek JM, Méchin H, Daures JP, Bousquet J: Visual analog scales can assess the severity of rhinitis graded according to ARIA guidelines. Allergy: European Journal of Allergy and Clinical Immunology 2007, 62(4):367-372.

17. Control of Allergic Rhinitis and Asthma Test" (CARAT) project [http://carat.med.up.pt/]

18. Van Oene CM, Van Reij EJF, Sprangers MAG, Fokkens WJ: Qualityassessment of disease-specific quality of life questionnaires for rhinitis and rhinosinusitis: A systematic review. Allergy:
European Journal of Allergy and Clinical Immunology 2007, 62(12):1359-137|.

19. Revicki $D$, Weiss $K B$ : Clinical assessment of asthma symptom control: Review of current assessment instruments. Journal of Asthma 2006, 43(7):48I-487.

20. Scopus database [http://www.scopus.com]

21. Murphy M, Black N, Lamping D, McKee C, Sanderson C, Askham J, Marteau T: Consensus development methods, and their use in clinical guideline development. Health Technol Assess. 1998, 2(3): I-88.
Publish with Bio Med Central and every scientist can read your work free of charge

"BioMed Central will be the most significant development for disseminating the results of biomedical research in our lifetime. "

Sir Paul Nurse, Cancer Research UK

Your research papers will be:

- available free of charge to the entire biomedical community

- peer reviewed and published immediately upon acceptance

- cited in PubMed and archived on PubMed Central

- yours - you keep the copyright

Submit your manuscript here:

http://www.biomedcentral.com/info/publishing_adv.asp
BioMedcentral 